\title{
A family study of the biochemical defects in Wilson's disease
}

\author{
J. F. SOOTHILL, J. D. BLAINEY, F. C. NEALE, \\ M. FISCHER-WILLIAMS, AND S. C. MELNICK
}

\begin{abstract}
From the Department of Experimental Pathology, Birmingham University Medical School, and the Departments of Biochemistry, Neurology, and Medicine, Queen Elizabeth Hospital, Birmingham
\end{abstract}

SYNOPSIS Estimations of serum copper, serum ceruloplasmin (immunochemical), and urinary amino-acids excretion (quantitative and chromatographic) in 44 healthy relatives of patients with Wilson's disease (39 from one family) are reported. Each technique revealed some abnormal $\underset{ }{\longrightarrow}$ individuals. Good agreement was obtained between the serum copper and serum ceruloplasmin $\bar{z}$ estimations and between the quantitative and chromatographic estimations of amino-acid excretion. Some individuals were abnormal to one or other of the pairs of tests only.

These results cast doubt on the hypothesis that the symptoms of Wilson's disease are secondary $\stackrel{\circ}{-}$ to a quantitative (or qualitative) abnormality of ceruloplasmin. They also suggest that the mode of inheritance of the biochemical defects may be more complicated than that of a simple recessive mutant gene.

Two of the relatives (one pregnant and one immediately post-partum) had a high serum copper level, as is expected in pregnancy, but normal serum ceruloplasmin. This suggests that the mechanism of control of the serum ceruloplasmin concentration may, normally, depend on the serum copper concentration.

It has been suggested that the symptoms of Wilson's disease may result from deposition of copper in the tissues caused by the deficiency of ceruloplasmin which is thought to be familial and to be transmitted as a recessive characteristic (Scheinberg and Gitlin, 1952; Bearn, 1953; Scheinberg, 1956). In several other familial disorders transmitted in a similar way, e.g., thalassaemia, symptomless biochemical abnormalities have been found in relatives who have therefore been assumed to be heterozygous for the mutant gene.

The only comprehensive family study of the relatives of patients with Wilson's disease was concerned with serum copper and urinary copper excretion (Neale and Fischer-Williams, 1958) although other abnormalities have been reported in individual symptomless relatives, e.g., aminoaciduria (Uzman and Hood, 1952) and ceruloplasmin deficiency (Grouchy, 1958). Neale and Fischer-Williams found abnormally low serum copper levels in a number of symptomless relatives, although the urinary copper excretion was normal. The low serum copper level in these subjects was assumed to reflect a deficiency of ceruloplasmin in symptomless heterozygotes.

One of the manifestations of Wilson's disease, which is attributed to deposition of copper in the renal tubules, is the aminoaciduria. In most typical cases all the biochemical abnormalities are apparent and it is difficult to determine which came first. We now report the results of a study of ceruloplasmin $N$ in asymptomatic relatives by an immunochemical $N$ technique to confirm the reported deficiency, and of $\mathcal{N}_{\mathrm{J}}$ amino-acid excretion to determine whether the $\omega$ aminoaciduria only occcurs in individuals with abnormal ceruloplasmin or whether it also occurs independently.

\section{MATERIALS AND METHODS}

Forty-four of the 48 relatives reported by Neale and $\frac{O}{\mathbb{D}}$ Fischer-Williams were studied. The same specimens of $\varrho$ serum and urine were used as in the previous report. Toluene was added to the urine specimens at the time of $\Omega$ 
collection, and the serum and urine specimens were stored frozen at $-25^{\circ} \mathrm{C}$. The subjects included 39 relatives from one family (family $A$ ) all of whom were parents, aunts, uncles, or first cousins ( 23 on the paternal side and 16 on the maternal side) of two siblings with typical Wilson's disease. The other five were four parents and one aunt of patients with typical Wilson's disease. All the subjects were examined by one of us. None showed clinical evidence of hepatolenticular degeneration. The few coexistent abnormalities were noted in the previous report.

The method and results of serum copper estimation were given in the previous paper (Neale and FischerWilliams, 1958), and the figures are included in Table I for comparison (normal ranges-male 76 to $133 \mu \mathrm{g}$./100 ml.; female 70 to $140 \mu \mathrm{g} . / 100 \mathrm{ml}$.).

Serum ceruloplasmin was estimated immunochemically by the method of Gell (1957). Results are expressed as a percentage of a standard serum from a healthy subject, which was stored frozen in divided portions. The method is one of titration, and has an error proportional to the concentration of the unknown (coefficient of variation $15 \%$ ). The ranges for 47 healthy males were $66-200 \%$ (mean 115\%) and for 48 healthy females $50-200 \%$ (mean $118 \%$ ). Of these, however, only one female was below $100 \%(50 \%)$ and a repeat estimation on the same individual was $75 \%$. It is doubtful if she can be regarded as normal and she may be heterozygous for the Wilson's gene. Ninety-eight per cent. of healthy females fell between 100 and $200 \%$, which we regard as the normal female range. The range of 10 estimations in four patients with hepatolenticular degeneration was $8-50 \%$ (mean $25 \%$ ).

Urinary free amino-acid excretion was estimated on aliquots of urine collected over 24 hours by the method of Rubinstein and Pryce (1959). The normal range of this method is $75-200 \mathrm{mg}$. $\alpha$ amino $\mathrm{N} / 24$ hours.

Urinary amino-acid chromatography was performed on $46 \times 57 \mathrm{~cm}$. Whatman No. 4 paper, using phenol: water and butanol : acetic acid : water (50:10:40) solvents (Dent, 1948). The chromatograms were developed by dipping the papers in $0.2 \%$ ninhydrin in acetone. Standard quantities of 5, 10, 20 and $40 \mu \mathrm{g}$. taurine were run on every paper and other amino-acids were compared visually with these spots. Creatinine estimations were done on all the urine samples to confirm the order of accuracy of the 24-hour collection. One ten thousandth of the 24-hour urine volume was applied to each paper to allow comparison of urine amino-acid concentration in different samples. The chromatograms were divided into four grades as follows:-

0 indicates a normal pattern

1 indicates slight excess of amino-acids normally present

2 indicates definite excess of normal amino-acids with small quantities of abnormal amino-acids

3 indicates gross aminoaciduria

The criteria of the normal pattern of amino-acid excretion have been discussed by Dent (1948). Grades 0 and 1 would be regarded as within this normal range, grades 2 and 3 as abnormal. Clearly the urine concentration and the volume placed upon the paper define the final pattern observed and a constant fraction of the 24- hour volume provide a means of comparison between different subjects. Nevertheless, the assessment of the pattern is at best only semiquantitative and the chromatograms classified as grade 2 cannot be regarded as necessarily pathological since the range of normal may be considerable (Berry, 1953). The detailed pattern of aminoacid excretion is shown for each subject (Table II), and it will be observed that leucine, valine, arginine, and lysine occur frequently in the group 2 classification. These amino-acids are not usually seen in the urine chromatograms of normal subjects.

\section{RESULTS}

Table I gives the results of these estimations. The serum ceruloplasmin estimations are in good general agreement with the previously reported serum copper results (Fig. 1) except for two sera, one from a pregnant and one from an immediately post-partum woman. The two individuals with serum ceruloplasmin less than the lower limit for the healthy subjects were No. 5 and No. 29, the patient's parents in family A. They also had two of the lowest serum copper levels, There are a considerable number of individuals in the lower part of the normal range who also have a low or low-normal serum copper

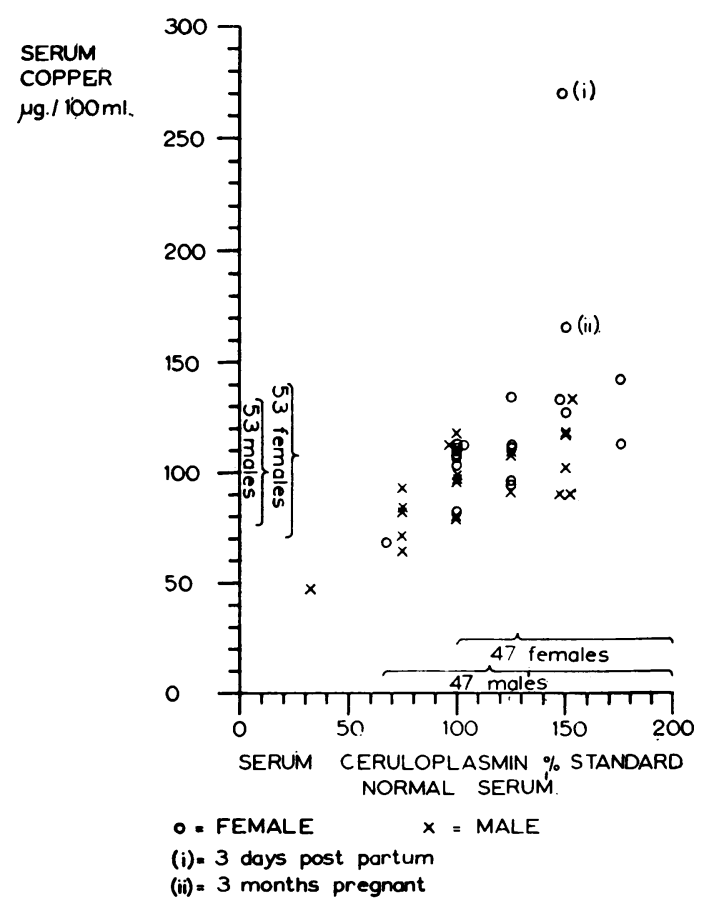

FIG.1. The relationship between serum copper and ceruloplasmin in asymptomatic relatives of patients with Wilson's disease. Ranges for healthy adults are given for the two sexes on each axis. 
TABLE I

ESTIMATIONS OF SERUM COPPER, CERULOPLASMIN, AND AMINOACIDURIA IN 44 HEALTHY RELATIVES OF PATIENTS WITH WILSON'S DISEASE

\begin{tabular}{|c|c|}
\hline $\begin{array}{l}\text { Subject } \\
\text { Number }\end{array}$ & $\operatorname{Sex}$ \\
\hline \multicolumn{2}{|c|}{ Paternal Relatives in Family $A$} \\
\hline 1 & $\mathbf{M}$ \\
\hline 2 & $\mathbf{F}$ \\
\hline 3 & $\mathbf{F}$ \\
\hline 4 & $\mathbf{F}$ \\
\hline 5 & $\mathbf{M}$ \\
\hline 6 & $\mathbf{M}$ \\
\hline 7 & $\mathbf{M}$ \\
\hline 8 (i) & $\mathbf{F}$ \\
\hline 9 & $\mathbf{M}$ \\
\hline 10 & $\mathbf{F}$ \\
\hline 11 & $\mathbf{F}$ \\
\hline 12 & $\mathbf{F}$ \\
\hline 13 & $\mathbf{F}$ \\
\hline 14 & $\mathbf{M}$ \\
\hline 15 (ii) & $\mathbf{F}$ \\
\hline 16 & $\mathbf{M}$ \\
\hline 17 & $\mathbf{M}$ \\
\hline 18 & $\mathbf{M}$ \\
\hline 19 & $\mathbf{M}$ \\
\hline 20 & $\mathbf{M}$ \\
\hline 21 & $\mathbf{M}$ \\
\hline 22 & $\mathbf{F}$ \\
\hline 23 & $\mathbf{M}$ \\
\hline
\end{tabular}

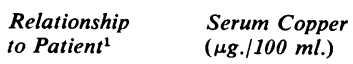

$\begin{array}{ll}\text { Age } & \begin{array}{l}\text { Relationship } \\ \text { to Patient }\end{array}\end{array} \quad \begin{aligned} & \text { Serum Copper } \\ & (\mu g . / 100 \mathrm{ml} .)\end{aligned}$

\section{Serum \\ Ceruloplasmin (\% of Normal Serum)}

Urinary Amino-acid Excretion (mg./24 hr.)

Maternal Relatives in Family A

$\begin{array}{lll}24 & \text { F } & 57 \\ 25 & \text { F } & 53 \\ 26 & \text { M } & 48 \\ 27 & \text { F } & 44 \\ 28 & \text { M } & 42 \\ 29 & \text { F } & 41 \\ 30 & \text { M } & 38 \\ 31 & \text { M } & 27 \\ 32 & \text { F } & 25 \\ 33 & \text { M } & 30 \\ 34 & \text { M } & 27 \\ 35 & \text { M } & 22 \\ 36 & \text { F } & 20 \\ 37 & \text { M } & 15 \\ 38 & \text { M } & 15 \\ 39 & \text { M } & 12\end{array}$

$\begin{array}{lr}\text { U } & 117 \\ \text { A } & 113 \\ \text { A } & 82^{2} \\ \text { A } & 110 \\ \text { F } & 47 \\ \text { U } & 100 \\ \text { C } & 97 \\ \text { C } & 269 \\ \text { C } & 126 \\ \text { C } & 113 \\ \text { C } & 96 \\ \text { C } & 95 \\ \text { C } & 133 \\ \text { C } & 91 \\ \text { C } & 165 \\ \text { C } & 71 \\ \text { C } & 64 \\ \text { C } & 99 \\ \text { C } & 112 \\ \text { C } & 96 \\ \text { C } & 84 \\ \text { C } & 103 \\ \text { C } & 82\end{array}$

150
100
100
100
33
150
100
150
175
125
125
150
125
150
75
75
100
100
100
75
100
75

100
117
126
$\frac{17}{33}$
148
190
101
108
153
92
782
89
78
150
150
44
157
157

Semiquantitative Chromatographic 흐 Grading of Urinary Amino-acids

$\begin{array}{rl}58 & \\ 56 & \\ 54 & \text { A } \\ 50 & \text { A } \\ 48 & \text { A } \\ 45 & \text { F } \\ 37 & \text { C } \\ 29 & \text { C } \\ 30 & \text { C } \\ 34 & \text { C } \\ 28 & \text { C } \\ 27 & \text { C } \\ 25 & \text { C } \\ 33 & \text { C } \\ 31 & \text { C } \\ 26 & \text { C } \\ 23 & \text { C } \\ 18 & \text { C } \\ 12 & \text { C } \\ 19 & \text { C } \\ 13 & 9\end{array}$

$\begin{array}{lr}\text { A } & 109 \\ \text { A } & 142 \\ \text { U } & 118 \\ \text { A } & 112 \\ \text { U } & 98 \\ \text { M } & 68 \\ \text { U } & 109 \\ \text { C } & 118 \\ \text { C } & 107 \\ \text { C } & 132 \\ \text { C } & 80 \\ \text { C } & 111 \\ \text { C } & 112 \\ \text { C } & 102 \\ \text { C } & 79 \\ \text { C } & 108\end{array}$

$\begin{array}{rr}100 & 53 \\ 175 & 18 \\ 100 & 190 \\ 125 & 69 \\ -66 & 124 \\ 125 & 183 \\ 150 & 99 \\ 100 & 96 \\ 150 & 225 \\ 100 & 219 \\ 100 & 137 \\ 150 & 270 \\ 100 & 66 \\ 125 & 225 \\ & 141 \\ & 115\end{array}$

Family $B$

$\begin{array}{lll}40 & \text { F } & 61 \\ 41 & \text { M } & 63 \\ 42 & \text { F } & 68\end{array}$

$\begin{array}{lr}M & 111 \\ \text { F } & 90\end{array}$

A

90
127

125
150

150

73
78

Family $C$

43
44

F

40
42

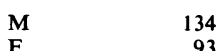

$\begin{array}{rr}34 & 125 \\ 93 & 75\end{array}$

${ }^{1} \mathbf{F}=$ father, $\mathbf{M}=$ mother, $\mathbf{U}=$ uncle, $\mathbf{A}=$ aunt, $\mathbf{C}=$ first cousin. (i) $=$ three days post-partum, (ii) $=$ three months' pregnant.

${ }^{2}$ Results regarded as abnormal by the criteria indicated in Fig. 3 are printed in italics.

level. Nine individuals have serum copper less than 85 g./100 ml. (Neale and Fischer-Williams's criterion of low or low-normal). Seven have a serum ceruloplasmin level less than $75 \%$ and only one of these is not included in the nine with low-normal copper (the patient's father in family C). The problem in interpreting these data, as a means of dividing these individuals into two populations, normal and abnormal, has already been discussed (Neale and

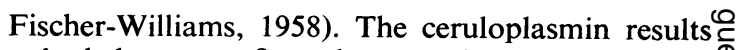
only help to confirm that certain individuals are abnormal and that certain individuals are normal for this parameter.

Fig. 2 shows that the two methods of studying $\underset{\mathbb{D}}{\stackrel{D}{Q}}$ amino-acid excretion give general agreement. Several $\frac{\mathbb{D}}{\stackrel{Q}{0}}$

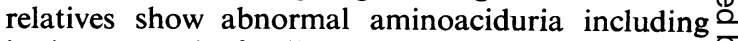
both parents in family A. The amino-acid pattern (Table II) is similar to that described in overt cases 8 
TABLE II

AMINO-ACIDS DETECTED BY PAPER CHROMATOGRAPHY IN URINE OF 42 HEALTHY RELATIVES OF PATIENTS WITH WILSON'S DISEASE

\begin{tabular}{|c|c|c|c|c|c|c|c|c|c|c|c|c|c|c|c|c|c|c|c|c|c|c|c|c|c|c|}
\hline 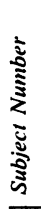 & 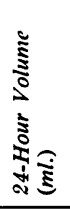 & 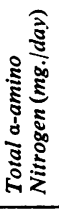 & 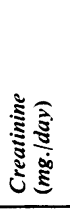 & 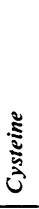 & 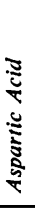 & ڤั & 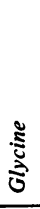 & : & 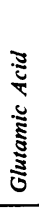 & 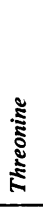 & 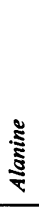 & & 竎 & 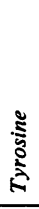 & 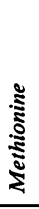 & $\underset{\frac{3}{3}}{\stackrel{3}{3}}$ & 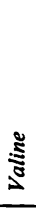 & $\begin{array}{l}\text { : } \\
\text { క్ }\end{array}$ & 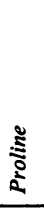 & 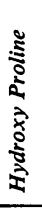 & $\begin{array}{l}\frac{5}{5} \\
\frac{5}{2} \\
\frac{5}{2}\end{array}$ & 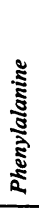 & 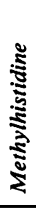 & 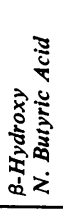 & 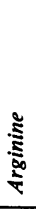 & 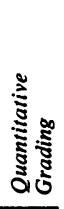 \\
\hline 1 & 620 & - & 1,220 & 2 & $\mathbf{t}$ & 2 & 2 & & 1 & & 1 & 1 & & $t$ & $t$ & & & & & & & & & & & 0 \\
\hline 2 & 1,460 & 100 & 1,190 & 1 & $t$ & 2 & 2 & $t$ & $t$ & $t$ & $t$ & 1 & & & & & & & & & & & & & & 0 \\
\hline 3 & 1,100 & 117 & $1,120^{\prime}$ & 1 & 1 & 2 & 2 & $t$ & & & 1 & 1 & & & & & & & & & & & & & & 0 \\
\hline 4 & 1,350 & 126 & 1,130 & 1 & & 1 & 2 & $t$ & $t$ & $t$ & 2 & 1 & $t$ & $t$ & $t$ & & & & & & & & & & $\mathbf{t}$ & 2 \\
\hline 5 & 2,180 & - & 1,460 & 4 & 3 & 3 & 3 & 1 & 2 & 2 & 4 & 4 & 1 & 1 & 3 & & $t$ & $t$ & & 1 & & $t$ & $t$ & $t$ & 2 & 3 \\
\hline 6 & 1,120 & 33 & 810 & 1 & t & 2 & 2 & & & $t$ & 2 & 1 & & & & & & & & & & & & $t$ & & 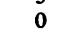 \\
\hline 7 & 2,380 & - & 1,450 & 1 & $t$ & 2 & 1 & $t$ & & $t$ & 1 & 1 & & $t$ & $t$ & & & & & & & & & & & 0 \\
\hline 8 & 1,230 & 148 & 1,030 & $t$ & 2 & 4 & 3 & & & 2 & 3 & 3 & & 1 & 1 & & 1 & & & & & & & & & 2 \\
\hline 9 & 1,130 & 190 & 1,650 & 2 & & 3 & 3 & $\mathbf{t}$ & & 1 & 2 & 2 & & 1 & 1 & & & & & & & & & & 1 & 1 \\
\hline 10 & 1,500 & - & 1,380 & 2 & $t$ & 2 & 2 & & 1 & & 1 & 1 & & $t$ & $t$ & & & & & & & & & & & 3 \\
\hline 11 & 1,020 & 101 & 1,010 & 2 & $t$ & 2 & 2 & & 1 & $t$ & 2 & 1 & 1 & 1 & 1 & & & & & & & & & & & 0 \\
\hline 12 & 1,740 & 108 & 1,270 & $t$ & & 3 & 2 & $\mathbf{t}$ & 1 & 1 & 1 & 1 & & & $t$ & & & & & & & & & & $t$ & 0 \\
\hline 13 & 1,460 & 153 & 1,140 & 2 & 1 & 3 & 2 & $\mathrm{t}$ & 2 & 1 & 1 & 2 & 1 & 1 & 1 & & $t$ & $t$ & & & & & & & 1 & 2 \\
\hline 14 & 1,185 & 92 & 1,960 & 2 & 1 & 3 & 2 & $t$ & & $t$ & 1 & 2 & 1 & $t$ & & & $t$ & 1 & & & & & & & $t$ & 2 \\
\hline 15 & 2,230 & - & 1,470 & $t$ & 1 & 2 & & $t$ & $\mathbf{t}$ & $t$ & 1 & 1 & & & & & & & & & & & & & $t$ & 1 \\
\hline 16 & 1,050 & 82 & 1,260 & 2 & & 2 & 1 & & & $t$ & $t$ & 1 & & & & & & & & & & & & & & 0 \\
\hline 17 & 740 & 89 & 1,020 & $t$ & & 2 & 2 & & & $t$ & $t$ & $t$ & & $t$ & & & & & & & & & & & & 0 \\
\hline 18 & 810 & 78 & 1,180 & 2 & 1 & 2 & 2 & & & $t$ & 1 & 1 & & $t$ & & & & $t$ & & & $t$ & & & & 1 & 2 \\
\hline 19 & 1,110 & 150 & 725 & 1 & & 2 & 2 & & & & $\mathrm{t}$ & $t$ & & & & & & & & & & & & & & 0 \\
\hline 20 & 1,130 & 150 & 870 & 1 & $\mathbf{t}$ & 2 & 3 & & $t$ & $\mathbf{t}$ & 1 & 2 & $t$ & $\mathbf{t}$ & $t$ & & $\mathbf{t}$ & & & & & & & & $t$ & 2 \\
\hline 21 & 1,080 & 44 & 131 & 3 & $t$ & 3 & 3 & & & 2 & 1 & 2 & & $t$ & & & & & & & & & & & & 1 \\
\hline 22 & 1,000 & 157 & 780 & $t$ & $t$ & 2 & 2 & & & t & 1 & 1 & & $t$ & & & & & & & & & & & & 0 \\
\hline 23 & 1410 & 157 & 1,240 & 3 & 2 & 4 & 4 & & & 1 & 2 & 2 & 1 & & & & & & & & & & & & & 1 \\
\hline 24 & 1,940 & 53 & 930 & $t$ & t & 1 & 2 & $\mathbf{t}$ & & $t$ & 1 & 1 & & & & & & & & & & & & & & 0 \\
\hline 25 & 360 & 18 & 284 & 1 & $t$ & 3 & 2 & $\mathbf{t}$ & & $t$ & 2 & 2 & & & & & & & & & & & & & $\mathbf{t}$ & \\
\hline 26 & 1,460 & 190 & 1,750 & 2 & & 2 & 1 & $\mathbf{t}$ & 1 & $t$ & 1 & 1 & $t$ & $\mathbf{t}$ & & & & $t$ & & & & & & & & 1 \\
\hline 27 & 1,410 & 69 & 1,120 & 1 & & 3 & 2 & & 1 & $t$ & 1 & 1 & & & & & & & & & & & & & & 0 \\
\hline 28 & 970 & 124 & 1,170 & $t$ & $t$ & & & 1 & 1 & $t$ & 1 & 1 & & $t$ & $t$ & $t$ & 1 & 2 & & & & & & $t$ & 1 & 2 \\
\hline 29 & 2,570 & 183 & 1,310 & 2 & 1 & 3 & 3 & $t$ & $t$ & $t$ & 1 & 1 & & $t$ & $t$ & & & & & & & & & $t$ & 1 & 2 \\
\hline 30 & 900 & 99 & 1,360 & 2 & 1 & 2 & 2 & 1 & & & 2 & 2 & $t$ & $\mathbf{t}$ & & & & & & & & & & & 1 & 0 \\
\hline 31 & - & 96 & - & 1 & 1 & 3 & 2 & $t$ & & $\mathbf{t}$ & 2 & 1 & $\mathbf{t}$ & t & $t$ & 1 & & & & & & & & & 1 & \\
\hline 32 & 1,380 & 225 & 1,870 & $t$ & $t$ & 3 & 2 & 2 & 1 & 2 & 2 & 1 & 1 & 1 & 1 & & & & & & & & & 1 & 3 & 3 \\
\hline 33 & 1,300 & 219 & 1,760 & 2 & 1 & 3 & 3 & & - & & 1 & 2 & 1 & $t$ & $t$ & & $t$ & $t$ & & & & & & & 1 & 2 \\
\hline 34 & 920 & 137 & 1,650 & 2 & $t$ & 3 & 3 & $t$ & & $t$ & 2 & 2 & & $t$ & $t$ & & & & & & & & & $t$ & $t$ & 3 \\
\hline 35 & 1,890 & 270 & 2,240 & 2 & 1 & 3 & 4 & $t$ & & 1 & 1 & 2 & & $t$ & $t$ & & & & & & & & $t$ & $t$ & $t$ & 3 \\
\hline 36 & 1,370 & 66 & 260 & 1 & t & 2 & 3 & $t$ & 1 & $t$ & $t$ & 1 & & & & & & & & & & & & & $t$ & \\
\hline 37 & 1,060 & 225 & 1,150 & 2 & $t$ & 2 & 3 & $t$ & 2 & $t$ & 1 & 1 & & $\mathbf{t}$ & & & & 1 & & & & & & & t & \\
\hline 38 & 1,340 & 141 & 1,270 & 1 & $t$ & 3 & 3 & & 2 & $t$ & 2 & 2 & & $t$ & & & & $t$ & & & & & & & 2 & 2 \\
\hline 39 & 1,240 & 115 & 460 & 1 & $t$ & 3 & 2 & & & $t$ & 2 & 2 & $t$ & $t$ & $t$ & & $t$ & $t$ & & & & & & & $t$ & 2 \\
\hline 40 & 800 & 73 & 750 & 2 & 1 & 2 & 2 & & & $t$ & 1 & 2 & & & & & & & & & & & $t$ & & & 0 \\
\hline 41 & 620 & 78 & 640 & 1 & & 2 & 2 & 1 & & $t$ & 2 & 2 & & & & & $t$ & $t$ & & & & & & & & 0 \\
\hline 42 & 1,490 & 63 & 640 & 1 & & 1 & 1 & & $\mathbf{t}$ & $t$ & $t$ & $t$ & & $\mathbf{t}$ & & & & & & & & & & & & \\
\hline
\end{tabular}

The concentration of each amino-acid is expressed semiquantitatively as trace and grades $1,2,3$, and 4, and the overall quantitative grading (see text and Table I) is given for comparison.

of hepatolenticular degeneration (Dent, 1948). Here again it is impossible to divide the subjects precisely into two populations, but certain individuals are definitely abnormal and others are normal. For further discussion we regard as abnormal the seven subjects selected on the basis either of having grade 3 chromatograms or more than $200 \mathrm{mg}$. of total $\alpha$-amino nitrogen per 24 hours, or both.

There is no evidence of an inverse relationship between the serum ceruloplasmin (and serum copper) and the amino-acid excretion. Some individuals, e.g., subjects 16 and 17, have low ceruloplasmin and copper with normal amino-acid excretion, and others, e.g., subjects 32 and 33 , have normal serum ceruloplasmin and copper, but abnormal amino-acid excretion.

A high serum copper level was found in two subjects (8 and 15$)$, who were pregnant or immediately post-partum, as would be expected in normal pregnancy. In both of these, however, serum ceruloplasmin was in the normal (non-pregnant) range.

\section{DISCUSSION}

Though our data are of limited value for estimating the incidence of abnormality in family $A$, certain 


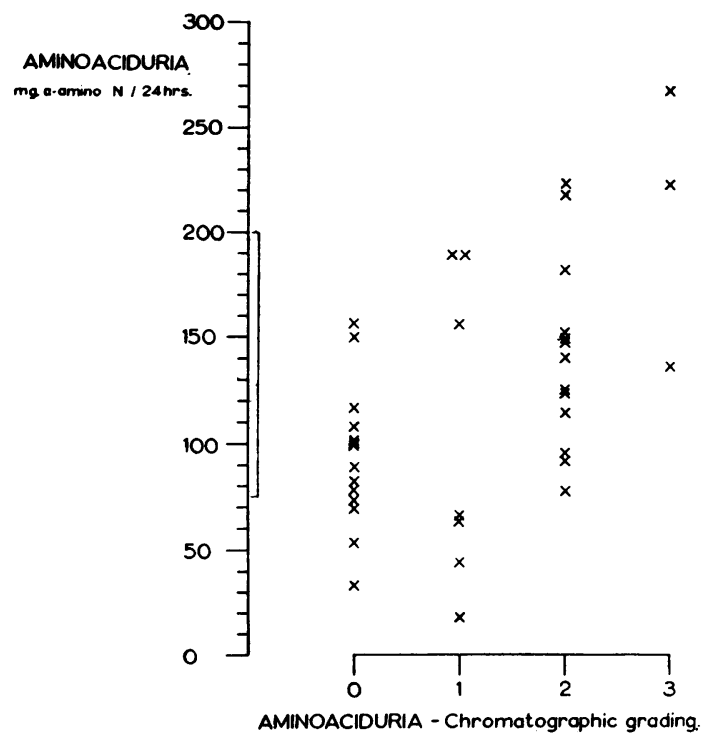

FIG. 2. The relationship between the chromatographic grading of aminoaciduria and the estimation of the 24-hour amino-acid excretion in asymptomatic relatives of patients with Wilson's disease. The normal range of the latter determination is shown.

individuals are sufficiently abnormal by each of the tests to demonstrate a familial abnormality which does not give rise to symptoms. Their relationship to the propositi is shown in the family tree (Fig. 3). The estimation of both ceruloplasmin and copper concentrations in parallel helps to define individuals abnormal in this respect. The technique for estimating copper is the more precise, but includes both the non-ceruloplasmin copper, which is raised in Wilson's disease, and the ceruloplasmin copper, which is reduced. The non-ceruloplasmin copper may also be raised in these affected relatives, though our data give no direct evidence. The two parallel techniques of estimating aminoaciduria were also mutually confirmatory. Amino-acid chromatograms of grade 3 are unquestionably abnormal, and, in all but one of such grade 3 urines, the quantitative estimations of $\alpha$-amino nitrogen were also raised. There is no doubt, moreover, that each of these abnormalities existed independently in certain individuals as well as occurring together.

Other reported studies of such families are somewhat contradictory. They comprise a report of nonquantitated deficiency of serum ceruloplasmin as shown by electrophoresis in starch gel (Grouchy, 1958) and the finding of abnormal urinary aminoacid excretion as shown by paper chromatography and formol titration in five out of six asymptomatic siblings in a family containing four cases of the full $\stackrel{0}{\overrightarrow{5}}$ disease (Uzman and Hood, 1952). All five were under 13 years old so the symptoms of the disease may still develop, but such an incidence is verysurprising if both parents were heterozygous for a $\overline{ }$ single recessive gene. An abnormal urinary peptide $\overline{\bar{c}}$. was also reported in these subjects; we did not $\widetilde{\Phi}$ find this in our series. On the other hand, Bearn and Kunkel (1954) failed to find abnormal amino- $\infty$ aciduria in 35 siblings of patients with hepatolenti- $\vec{O}$ cular degeneration, using a qualitative screening $=$ technique. Although the family reported by Uzman ${ }_{\sigma}^{\omega}$
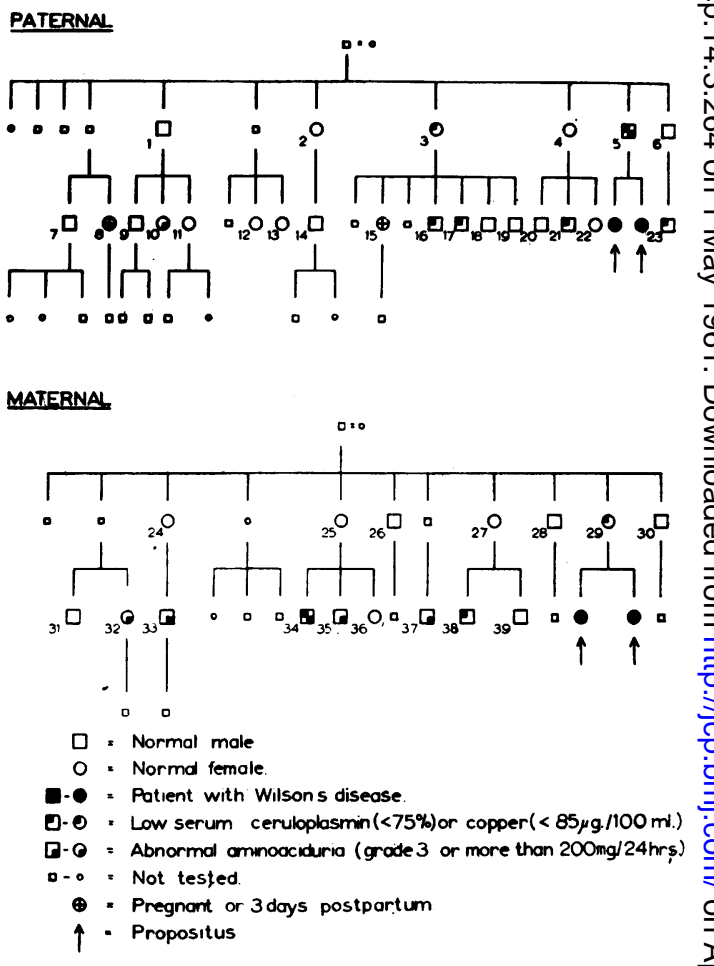

FIG. 3. Family tree of family $A$ (paternal and materna? relatives of the two propositi). The criteria for defining eachn individual as normal or abnormal are arbitrary and are discussed in the text. Each one may be assessed in the lighN of the results given in Table I.

and Hood (1952) and ours could both have had symptomless familial aminoaciduria independen of Wilson's disease, this seems an unlikely coincidence. There have been no reports of studies of ceruloplasmin and aminoaciduria in the same्ष्त family.

A genetically controlled deficiency of cerulo® plasmin has often been regarded as the basic abnor? mality in Wilson's disease (Scheinberg and Gitlin 
1952; Bearn, 1953; Scheinberg, 1956). It has been suggested that this results in an excess of free copper in the blood, which is deposited in brain, liver, kidneys, etc., producing the characteristic morbid anatomical and functional abnormalities, including the aminoaciduria. Three clinically typical cases of Wilson's disease have recently been reported (SassKortsak, Cherniak, Geiger, and Slater, 1959; Rosenoer and Franglen, 1959) in which the serum ceruloplasmin was quantitatively normal but abnormal in its property of combining with copper. These patients had the abnormally increased copper excretion, which is characteristic of the disease, and abnormal deposition of copper in the tissues.

The detection in the same healthy relatives of patients with Wilson's disease of abnormal aminoaciduria but normal serum copper and ceruloplasmin and normal copper excretion make. it unlikely that the aminoaciduria is caused by copper deposition in the kidney, whether this is due to quantitative or qualitative abnormality of the ceruloplasmin. The individuals with abnormal serum ceruloplasmin or copper but normal amino-acid excretion are in keeping with previous reports of normal amino-acid excretion in patients with the overt disease (Stein, Bearn, and Moore, 1954; Bickel, Neale, and Hall, 1957). This makes the alternative theory (Uzman and Hood, 1952), that the aminoaciduria is the cause of the disturbance of copper metabolism, untenable. It is, of course, possible that some of the younger of these relatives may still develop the disease but this is unlikely in the case of the two parents (Nos. 5 and 29) who were over 40 years old.

The attraction of the ceruloplasmin deficiencycopper deposition-tissue damage hypothesis of this disease lies in its simplicity, and in its ability to explain all the scattered abnormalities. But there is no precise correlation between the extent of the ceruloplasmin-copper abnormality and the extent of tissue damage and of symptoms. At first the improvement of some patients when treated with copperremoving drugs, such as dimercaprol and penicillamine, appeared to confirm this hypothesis, but recently doubt has been cast on whether their effect depends on their copper-removing action (Walshe, 1960). If, as our results suggest, the renal abnormality is independent of the ceruloplasmin-copper abnormality the hypothesis becomes less attractive. It is equally possible that the cirrhosis of the liver is related to the basic hepatic abnormality of ceruloplasmin production rather than to the copper deposition. There may be a genetically determined deficiency of a widespread tissue enzyme, the deficiency of which makes the liver unable to produce ceruloplasmin and causes cirrhosis; in the brain, it produces mental defect, tremor, etc., and in the kidney aminoaciduria. The generalized copper deposition may be a result of the liver defect and not a cause. Other modifying genes could presumably modify the manifestation of the mutant gene in each one of these situations independently, thus explaining the great variation in the relative severity of the various clinical features in different patients, and the independence of the aminoaciduria and the ceruloplasmin-copper abnormality in our symptomless relatives.

Our data are of limited value for detailed genetic analysis because the limits of normality of the tests applied are difficult to define (particularly for the aminoaciduria) and two of them are only semiquantitative, so that a statistical comparison of the relatives with the normal population is difficult. Some observations of genetic interest may be made, however. First, the parents of the propositi in family A have much the lowest serum ceruloplasmin and copper levels of all the symptomless relatives. In the theory of inheritance as a simple recessive characteristic, there is no reason why they should differ from any other individuals in the family who are heterozygous for the gene. This suggests that the system is more complex, raising the possibility of modifying genes. Second, the detection of only one doubtfully abnormal test (serum ceruloplasmin $75 \%$ in the father of family C) in the four parents of the propositi in the other families strongly suggests a difference between family $A$ and the other two families. (There is no reason why a clinical syndrome may not be inherited in different ways, in different families.)

The discrepancy of copper and ceruloplasmin estimations in the two pregnant (or post-partum) subjects suggests that the disturbance of copper metabolism, which normally occurs in pregnancy (Markowitz, Gubler, Mahoney, Cartwright, and Wintrobe, 1955), may have revealed a latent defect in these individuals. Both showed the high serum copper level (269 and $165 \mu \mathrm{g} . / 100 \mathrm{ml}$.) expected in pregnancy, but the serum ceruloplasmin was within normal limits $(150 \%)$. This is in contrast to our findings in 11 other pregnant women, all of whom had serum ceruloplasmin levels between 200 and $400 \%$ of standard 'normal' serum. These high levels in normal pregnancy were commensurate with the high serum copper, so that they continued the linear relationship shown by the other subjects in Fig. 1 and are in keeping with other reports (Markowitz et al., 1955; Scheinberg, 1956). From this discrepancy one can speculate that in pregnancy the raised serum ceruloplasmin normally occurs as a direct result of an increase in serum copper and that these individuals, presumably heterozygous for the mutant gene, 
because of their defect, are incapable of fully compensating by producing increased ceruloplasmin. This implies that there is a mechanism of physiological control of the serum ceruloplasmin production, depending on the serum copper concentration. One other piece of circumstantial evidence for this hypothesis is that the serum ceruloplasmin is raised in cirrhosis associated with biliary obstruction (Bearn and Kunkel, 1954). Copper is excreted in the bile, so the elevation of ceruloplasmin in biliary obstruction could be secondary to copper retention.

It has already been suggested (Scheinberg and Morell, 1957) that release of copper from ceruloplasmin in the blood of the alimentary tract, possibly as a result of a low oxidation potential, prevents excessive copper absorption. If both these hypotheses were correct such a mechanism of reciprocal dependance would normally be expected to produce a very precise equilibrium, such as is indeed found in the remarkably constant serum copper concentration.
We are grateful to Professor P. G. H. Gell and Profess J. R. Squire for advice and encouragement, and to DF. G. Hall, under whose care the patients were studied.

\section{REFERENCES}

Bearn, A. G. (1953). Amer. J. Med., 15, 442. , and Kunkel, H. G. (1954). J. clin. Invest., 33, 400.

Berry, H. K. (1953). Amer. J. phys. Anthrop., 11, 559.

Bickel, H., Neale, F. C., and Hall, G. (1957). Quart. J. Med., $\frac{20}{26}$ 527.

Dent, C. E. (1948). Biochem. J., 43, 169.

Gell, P. G. H. (1957). J. clin. Path., 10, 67.

Grouchy, J. de (1958). Rev. franç. Et. clin. biol., 3, 621.

Markowitz, H., Gubler, C. J., Mahoney, J. P., Cartwright, G. and Wintrobe, M. M. (1955). J. clin. Invest., 34, 1498.

Neale, F. C., and Fischer-Williams, M. (1958). J. clin. Path., 11, 44. Rosenoer, V. M., and Franglen, G. (1959). Lancet, 2, 1163.

Rubinstein, H. M., and Pryce, J. D. (1959). J. clin. Path., 12, 80 $\vec{D}$, Sass-Kortsak, A., Cherniak, M., Geiger, D. W., and Slater, R. Y. (1959). J. clin. Invest., 38, 1672.

Scheinberg, I. H. (1956). In Neurochemistry, pp. 52-63, ed. S. R Korey and J. I. Nurnberger. Cassell, London; Hoeber, Nefw York.

- and Gitlin, D. (1952). Science, 116, 484

, and Morell, A. G. (1957). J. clin. Invest., 36, 1193.

Stein, W. H., Bearn, A. G., and Moore, S. (1954). Ibid, 33, 410. Uzman, L. L., and Hood, B. (1952). Amer. J. med. Sci., 223, 392. Walshe, J. M. (1960). Lancet, 1, 188. 